\section{Pauling and Frech reply}

To the Editor:

We thank Dr. Hughes for his interest ${ }^{1}$ in our article ${ }^{2}$ reporting factors influencing Raynaud phenomenon (RP) symptom reporting in patients with systemic sclerosis (SSc). We presented data demonstrating differences in Raynaud symptom reporting using the Raynaud Condition Score (RCS) diary depending on season of enrollment ${ }^{2}$. A weaker-than-expected relationship between external temperature (using Meterological Office data) and contemporaneous collection of the RCS diary (Spearman $\rho \sim-0.25$ ) suggests that other factors beyond cold exposure may contribute to Raynaud burden in $\mathrm{SSc}^{2}$. Dr. Hughes has presented an analysis of the effect of season on Raynaud by evaluating the influence of seasonal variation on Internet searches using the term "Raynaud phenomenon". Consistent with an anticipated relationship between cold exposure and Raynaud symptoms, a clear pattern emerges highlighting increasing health-seeking Internet search activity for Raynaud during the colder months, with troughs during warmer seasons. An evaluation of mean monthly UK temperatures over the same period of analysis suggests seasonal factors beyond external temperature may contribute to information-seeking behavior for Raynaud symptoms. The chart of UK Internet search activity for RP presented by Dr. Hughes revealed a pronounced spike during January 2008 (> 70 "peak popularity" units) compared to January 2010 ( $<40$ units), despite average UK temperatures within those months being $5.3^{\circ} \mathrm{C}$ and $0.9^{\circ} \mathrm{C}$, respectively (Figure 1$)^{3}$. Seasonal factors beyond external temperature may therefore contribute to variation in RP symptoms (and information-seeking Internet searches), perhaps including humidity, precipitation, and wind chill factor. A range of factors beyond cold exposure has been associated with precipitating RP symptoms in SSc, particularly situations associated with temperature change (e.g., entering air-conditioned premises, damp/water exposure, chilled food aisles in grocery stores), and emotional stress ${ }^{4,5}$. Extreme cold can lead to reluctance to go outdoors and increased reliance upon others, which could mitigate RP symptoms (at the expense of reduced social participation) ${ }^{4}$.
It is expected that the majority of the Internet searches presented by Dr. Hughes will have been made by people affected by "primary RP." Once again, there are expected (and unexpected) associations between local climate and Raynaud symptoms. There is marked geographic variation in prevalence estimates of primary RP across different countries, ranging from $2.1 \%$ of females in Japan, to $22.4 \%$ in Scandinavia ${ }^{6}$. Such variation is typically attributed to differences in climate and considered in the context of digital vasoconstriction representing an important, and entirely appropriate, thermoregulatory response to cold exposure. Such observations have led people to question the very existence of primary RP, proposing instead that "these are healthy people whose cold and colourful hands are more obvious (and) occasionally more troublesome, than that of their peers"7. Additional cultural and social (and possibly ethnic) factors may also influence the relationship between climate and Raynaud symptoms. Community-based studies in South Carolina and 4 geographic regions of France supported a direct relationship between local climate and RP prevalence, but this relationship was challenged by the subsequent identification of a comparatively lower prevalence of RP symptoms in southern Estonia despite its colder winters ${ }^{7,8,9}$. Cultural, ethnic, and clinical phenotypic factors appear to contribute to geographic variation in RP symptom burden in SSc. Data from separate clinical trials of tadalafil for SSc-RP that each enrolled patients in winter identified a higher frequency and burden of RP symptoms in patients enrolled in Lucknow, India (mean 3.5 Raynaud attacks/day and mean daily RCS of 5.28/10) compared to Ann Arbor, Michigan (2.9 attacks/day and mean RCS 3.76/10), despite an expected difference in mean daily temperature of $\sim 20^{\circ} \mathrm{C}\left(+16^{\circ} \mathrm{C}\right.$ to $\left.-4^{\circ} \mathrm{C}\right)$ across the 2 regions ${ }^{10}$.

What are the implications of such observations for clinical practice and therapeutic trials of RP? The relationship between climate and geographic variation in RP prevalence highlights the importance of maintaining core temperature when counseling patients on RP management. Reassuring patients with primary RP that digital vasoconstriction is an important physiological response and that, for many, RP symptoms represent an exaggerated healthy state that, while intrusive, are not dangerous may allay health anxiety.

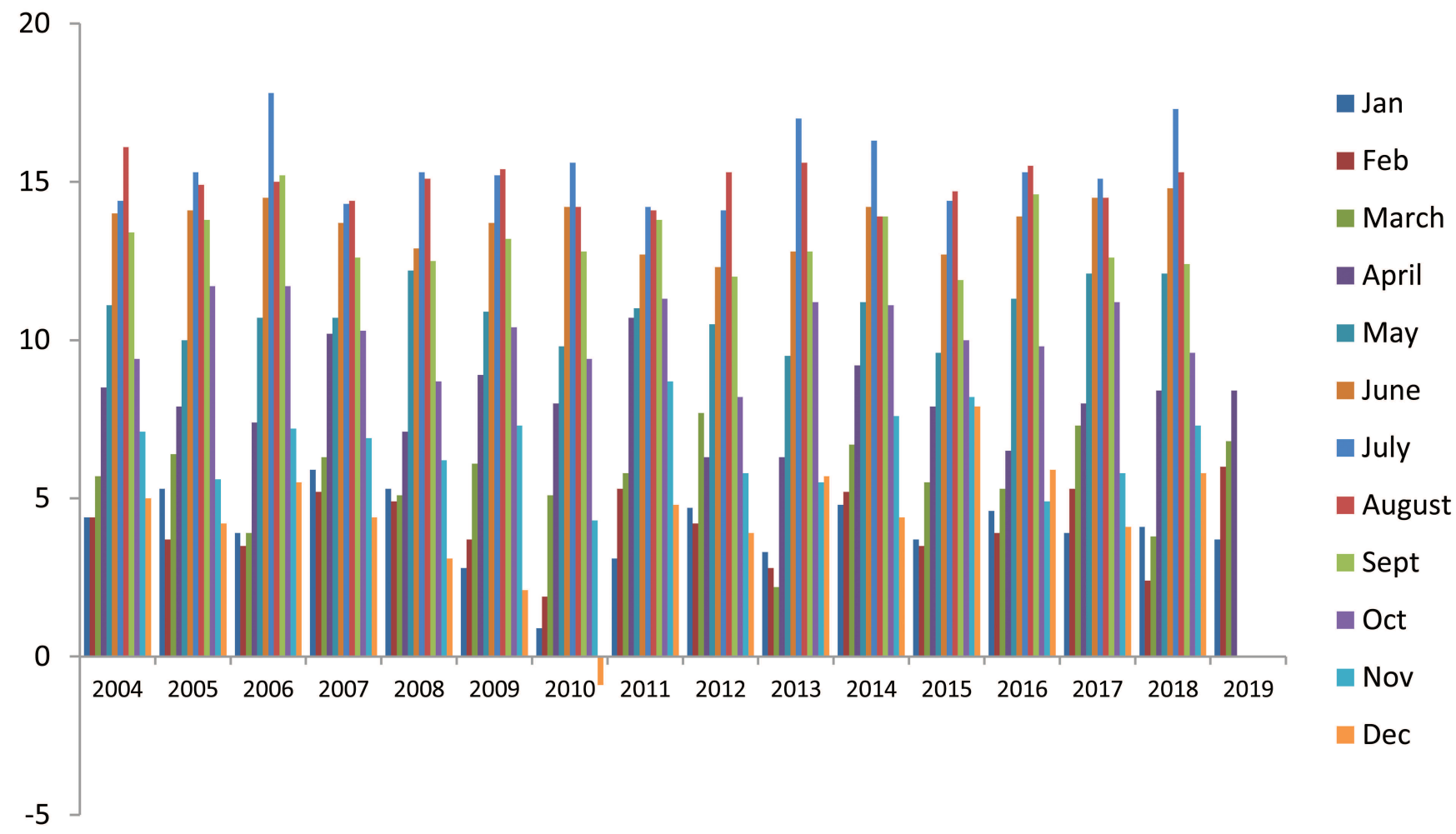

Figure 1. Monthly UK mean temperatures 2004-present (degrees C), using UK meteorological data available from the Meteorological Office UK and regional series datasets ${ }^{3}$.

Personal non-commercial use only. The Journal of Rheumatology Copyright @ 2019 . All rights reserved. 
Therapeutic trials have traditionally enrolled patients over the winter months, but 12- to 16-week assessments of primary endpoints risk seasonal variation in weather influencing outcome assessments - a somewhat overlooked factor that may contribute to the high placebo response typically observed in RP clinical trials ${ }^{10}$. We agree with Dr. Hughes' suggestion that shorter-term clinical trials over 1-2 weeks are preferable, but only if outcome measures can be validated to facilitate this (e.g., objective microvascular imaging or retrospective self-administered patient-reported outcome instruments $)^{10}$. Weather (certainly across much of Europe and North America) can be fickle, with frequent swift and marked variations that could influence the findings of RP clinical trials (Figure 2). It is perhaps impossible to entirely mitigate the effect of weather when evaluating RP, but understanding its contribution can aid interpretation of study findings and help optimize clinical trial design.

JOHN D. PAULING ${ }^{\circledR}$, PhD, BMedSci, FRCP, Royal National Hospital for Rheumatic Diseases (at Royal United Hospitals), and Department of Pharmacy and Pharmacology, University of Bath, Bath, UK; TRACY M. FRECH ${ }^{\circledR}$, MD, MS, University of Utah and Salt Lake Regional Veterans Affairs Medical Center, Salt Lake City, Utah, USA. Address correspondence to J.D. Pauling, Senior Lecturer and Consultant Rheumatologist, Royal National Hospital for Rheumatic Diseases, Upper Borough Walls, Bath, BA1 1RL, UK. E-mail: JohnPauling@nhs.net

\section{REFERENCES}

1. Hughes M. Effect of season on Internet searches for information on Raynaud phenomenon. J Rheumatol 2019;46:1543-4.

2. Pauling JD, Reilly E, Smith T, Frech TM. Factors influencing Raynaud condition score diary outcomes in systemic sclerosis. J Rheumatol 2019 May 15 (E-pub ahead of print).

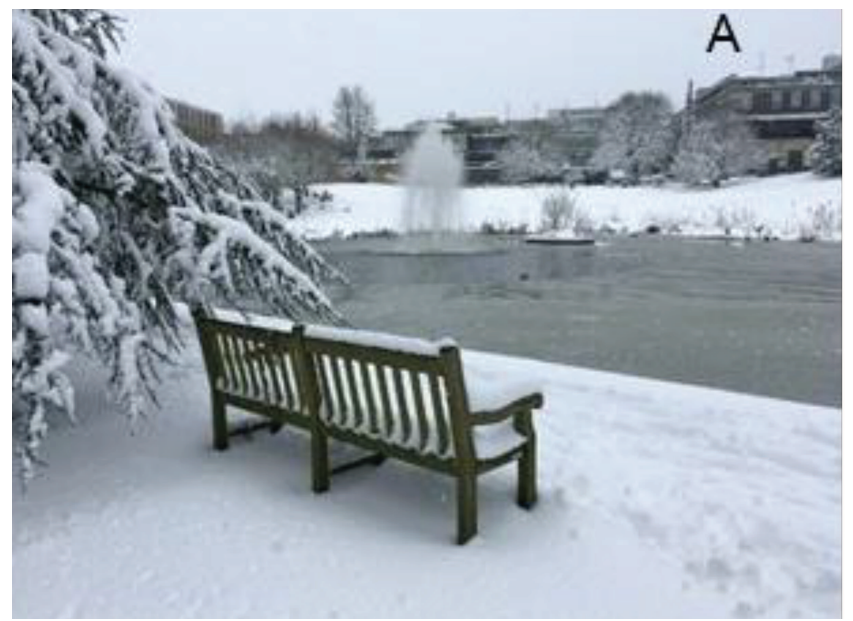

3. Meterological Office UK and regional series datasets, 2019 [Internet. Accessed June 6, 2019.] Available from: www.metoffice.gov.uk/pub/data/weather/uk/climate/ datasets/Tmean/date/UK.txt

4. Pauling JD, Domsic RT, Saketkoo LA, Almeida C, Withey J, Jay H, et al. Multinational qualitative research study exploring the patient experience of Raynaud's phenomenon in systemic sclerosis. Arthritis Care Res 2018;70:1373-84

5. Pauling JD, Saketkoo LA, Matucci-Cerinic M, Ingegnoli F, Khanna D. The patient experience of Raynaud's phenomenon in systemic sclerosis. Rheumatology 2019;58:18-26.

6. Garner R, Kumari R, Lanyon P, Doherty M, Zhang W. Prevalence, risk factors and associations of primary Raynaud's phenomenon: systematic review and meta-analysis of observational studies. BMJ Open 2015;5:e06389.

7. Hadler NM. "Primary Raynaud's" is not a disease or even a disorder; it's a trait. J Rheumatol 1998;25:2291-4.

8. Maricq HR, Carpentier PH, Weinrich MC, Keil JE, Palesch Y, Biro $\mathrm{C}$, et al. Geographic variation in the prevalence of Raynaud's phenomenon: a 5 region comparison. J Rheumatol 1997;24:879-89.

9. Valter I, Maricq HR. Prevalence of Raynaud phenomenon in Tartu and Tartumaa, southern Estonia. Scand J Rheumatol 1997; 26:117-24

10. Pauling JD, Nagaraja V, Khanna D. Insight into the contrasting findings of therapeutic trials of digital ischaemic manifestations of systemic sclerosis. Curr Treatm Opt Rheumatol 2019;5:85-103.

First Release July 15 2019; J Rheumatol 2019;46:11; doi:10.3899/jrheum.190565

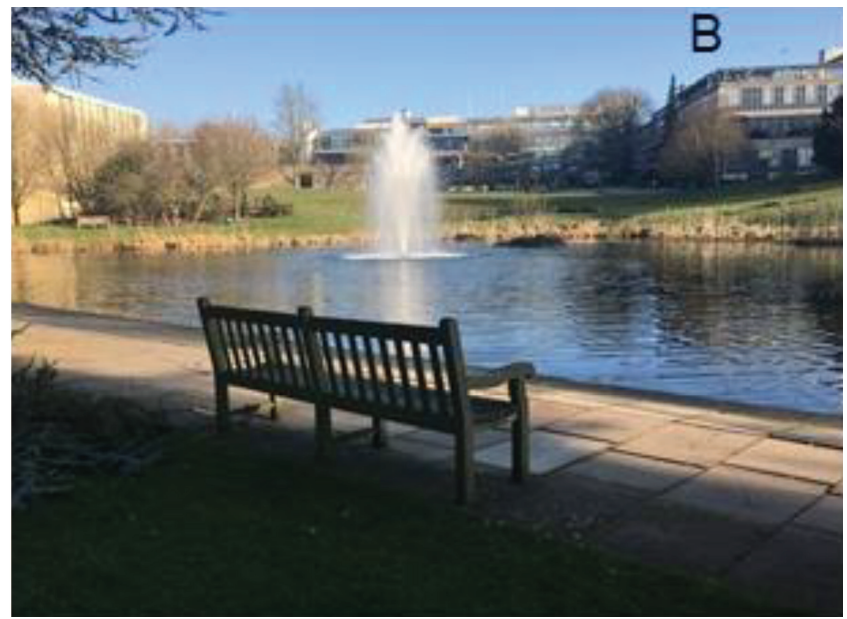

Figure 2. Short-term marked variation in local weather could greatly influence Raynaud phenomenon clinical trial outcomes. A. The University of Bath campus, February $1,2019\left(-2^{\circ} \mathrm{C}\right)$, and (B) the same location on February $27,2019\left(+16^{\circ} \mathrm{C}\right)$. 